\title{
Unintentional injury deaths in adult Finnish population: nationwide statistics between 1971 and 2016
}

Pekka Kannus ${ }^{1,2}$. Seppo Niemi ${ }^{1}$, Jari Parkkari ${ }^{3}$, Harri Sievänen ${ }^{1}$,

1Injury \& Osteoporosis Research Center, UKK Institute for Health Promotion Research, Tampere, Finland

2 Medical School, University of Tampere, and Department of Orthopedics and Trauma Surgery, Tampere University Hospital, Tampere, Finland

3 Tampere Research Center of Sports Medicine, UKK Institute for Health Promotion Research, Tampere, Finland.

Keywords: Adult Finns; Secular trends; Unintentional injury deaths

Correspondence to:

Prof. Pekka Kannus, MD, PhD

UKK Institute,

P.O. Box 30,

FIN-33501 Tampere,

FINLAND

phone: +358-3-282-9111

fax: $\quad+358-3-282-9200$

e-mail: pekka.kannus@uta.fi 
Abstract

This study determined the nationwide trends in unintentional injury deaths of adult Finns. For this purpose, we obtained from the Finnish Official Cause-of-Death Statistics (OCDS) the data for persons 15 years of age or older whose deaths occurred between 1971 and 2016 due to an unintentional injury.

During the study period, a steep decline occurred in road traffic crashes. The death rate (per 100,000 persons) of women's road traffic crashes was 16 in 1971 but only 2 in 2016. Traffic caused much more deaths in men than women, but the declining trend in men's death rates was also clear, from 46 in 1971 to 7 in 2016. Concurrently, falls became the leading category of unintentional injury death in both genders. In women, the rate of fall-induced deaths increased from 16 in 1971 to 23 in 2016. In men, this rate rose from 14 in 1971 to 29 in 2016.

Unintentional injury deaths in road traffic crashes declined drastically among adult Finnish population in 1971-2016. In contrast, the increase in their fall-induced deaths was of concern. Effective preventive actions should be started to control this development.

Keywords: Adult Finns; Secular trends; Unintentional injury deaths 


\section{Introduction}

Injuries are substantial health concern, a common cause of impairment, disability and years of life lost, and a major contributor to health care costs [1-10]. In Finland, over 1.2 million accidents, assaults or self-harms result in physical injury annually and unintentional injury is the leading cause-of-death for persons aged 15 to 44 years and the fourth leading cause-of-death among all age groups combined $[8,11]$. Although the injury-related mortality rate declined in the $20^{\text {th }}$ century [5, 9, 10], the rate has increased since 1990s [1, 3, 5, 6, 12].

Previously we reported that unintentional injury deaths of adult Finns in road traffic crashes declined in 1971-2008 while poisoning deaths due to alcohol and other substances increased [8]. We have now followed the nationwide database for 46 years (to the end of 2016) to assess the current secular trends in unintentional injury mortality rates among persons 15 years of age or older in Finland, an EU-member country with a well-defined Caucasian population of 5.5 million people. 


\section{Methods}

We obtained from the Finnish Official Cause-of-Death Statistics (OCDS) the data for persons 15 years of age or older who died because of an unintentional injury between 1971 and 2016. This statutory register has been computer-based and unchanged since 1971, and since its inception, it has been updated and reviewed for data quality by the Cause-of-Death Bureau at Statistics Finland [11]. The Finnish OCDS contain data on age, sex, marital status, place of residence, and place, cause and time of death of the deceased. The main categories of death from unintentional injury are road traffic crashes, water traffic crashes, falls, drownings, alcohol poisonings, and other poisonings. For deaths from intentional injury, the main categories are suicides and homicides.

The Finnish OCDS are, in practice, 100\% complete, since each death, its official certificate (issued by the physician who certified the death), and the corresponding biographical data in our computerized population register are cross-checked [11]. The accuracy of the data is, in turn, maximized by three independent examinations of the codes of the death certificate $[7,8,11]$. In injury-based deaths, the accuracy of the Finnish death certificates and their cause-of-death codes are verified further by autopsies performed in over $90 \%$ of these deaths $[7,8,11]$.

The mortality data were drawn from the entire 15-year-old or older population of Finland, which was 3504845 in 1971 and 4600203 in 2016 [13]. Thus, the below given absolute numbers and rates (per 100,000 persons) of deaths were not cohort-based estimates but true descriptions of the entire target population, and therefore, the study, in full agreement with our previous studies [7, 8], did not use statistical analyses with confidence intervals intrinsically needed for cohort or samplebased estimations with sampling variability . 


\section{Results}

\section{Women}

Among Finnish women, falls were the leading cause of unintentional injury death for the entire period 1971-2016 (Fig. 1). The number and rate of their fall deaths rose until the end of 1990s after which these figures have stayed relative stable (Fig. 1). In 2016, 548 women died due to a fall with the rate (per 100,000 persons) of 23.

A steep decline occurred in women's road traffic crashes. The death rate (per 100,000 persons) of women’s road traffic crashes was 16 in 1971 but only 2 in 2016 (Fig. 1). In 1971, 296 Finnish women died in road traffic crashes while this number was no more than 43 in 2016 (Fig. 1).

The number and rate of women's deaths due to alcohol or other poisoning was relatively low during the entire study period (Fig. 1). These figures increased until 2008 after which they started to decline. Drownings and water traffic crashes were uncommon causes of death in Finnish women during 1971-2016 (Fig. 1).

\section{Men}

Among Finnish men, a drastic decline in both the number and rate of injury deaths between 1971 and 2016 occurred in road traffic crashes (Fig. 2). The death rate (per 100,000 person-years) of men's road traffic crashes was 46 in 1971 but only 7 in 2016. The corresponding numbers were 760 victims vs. 160 victims, respectively (Fig. 2).

As in women, the number and rate of men's fall-induced deaths increased during the study period, falling being clearly the leading category of men's unintentional injury death in 2016 (Fig. 2). Parallel to women, the increasing trend in men's fall deaths leveled off at the beginning of the new millennium (Fig. 2). In 2016, 648 men died due to a fall with the rate (per 100,000 persons) of 29. These numbers were higher than those in women.

There was a notable rise in the number and rate of men's unintentional alcohol and other poisoning deaths, especially since 2003. Fortunately, this trend turned to a clear decline after the year 2007 (Fig. 2). During the entire study period of 1971-2016, men’s deaths due to drownings and water traffic crashes have shown a steady decline (Fig. 2). 


\section{Discussion}

Finland has experienced a drastic change in the profile of unintentional injury deaths between 1971 and 2016 with falls (and partly poisonings) replacing road traffic crashes as the leading causes of injury-induced death. The decline in traffic-induced deaths has been remarkable, particularly given that the Finnish car pool and driven kilometers per year have multiplied during the recent decades. The reasons for this positive time trend are multifactorial, but the most likely explanation is improved traffic safety, perhaps as the result of the multidimensional traffic safety program conducted in Finland since the late 1960s [8]. The program has included road and traffic planning and legislation, more comprehensive traffic supervision and control (particularly controlling speeds and driving under the influence of alcohol and illicit drugs), improved vehicular safety (car body, seats, seat belts, air bags, and child safety-seat restraints), and intense promotion of the use of bicycle helmets and other traffic safety issues among the general public. More rapid access to emergency services and improved trauma care is an additional factor that may contribute to the above-noted decline in fatal traffic injuries [8-10].

According to our findings, falls are currently the number one cause in injury-induced deaths among Finnish men and women:-most of the victims are elderly persons and they are also responsible for most of the changes seen in fall-deaths by time_[7, 8]; -and the number of fallinduced deaths is expected to increase with continuous aging of the population $[7,13]$. On the other hand, the current study shows that the number and rate of fall-induced deaths have stabilized in recent years (Figs. 1 and 2). One reason for this positive development could be that the average functional ability of the older adults has improved in Finland thus resulting in less falls and related injuries [14-16]. In addition, more rapid access to emergency services and improved trauma care may have contributed to the observed stabilization of the fall-death rate._Nevertheless, the number of older adults in Finland is rising so rapidly that there is a clear need for effective falls prevention actions to reduce the number of fall-induced injuries and related deaths. This should receive high priority in our health policy because older individuals' falls prevention actions are effective and the measures can be organized cost-effectively $[17,18]$.

The rise in poisoning deaths due to alcohol and other substances (mostly psychotropic drugs) at the beginning of the new millennium (years 2003-2007) was alarming, but fortunately this trend turned to a clear decline in both genders rather soon after the year 2007 (Figs. 1 and 2). Exact reasons for this quick rise and subsequent decline remained unknown, but most likely our alcohol 
and drug policy - after quick rethinking, education, counselling, and restrictive actions - was able to react effectively to increased substance consumption [19].

A limitation in the current study is that our findings in Finland can not be directly generalized to other nations. On the other hand, Finland, an EU-member state with a well-defined Caucasian population of 5.5 million people, is a rather typical representative of Northern Europe, and therefore our injury profile observations and their secular trends should not deviate much from those in other advanced societies.

\section{Conclusions}

Unintentional injury deaths in road traffic crashes declined drastically among adult Finnish persons during 1971-2016. In contrast, increase in their fall-induced deaths was notable, and therefore effective preventive actions should be initiated to control this development.

\section{What is already known on the subject}

- Injuries are a major public health issue and among the leading causes of death worldwide.

- In Finland, over 1.2 million accidents, assaults or self-harms lead to physical injury annually.

\section{What this study adds}

- Unintentional injury deaths in road traffic crashes declined dramatically in adult Finns between 1971 and 2016.

- However, simultaneous increase in their fall-induced deaths was of concern.

- Effective preventive actions should be started to control the latter development.

Acknowledgements The authors thank Statistics Finland for good co-operation. 
Funding This study was funded by the Comparative State Research Financing of the Expert Responsibility Area of Tampere University Hospital, Tampere, Finland (Grant no 9V015). This organization had no involvement in the (1) study design; (2) collection, analysis and interpretation of data; (3) writing of the manuscript; and (4) decision to submit the manuscript for publication.

Competing interests The authors have no competing interests.

Ethics approval As a register-based blinded analysis, the study did not have identifiable individual subjects and therefore it (according to the Finnish Law of Medical Research) did not need ethics approval.

\section{References}

1. CDC. Increases in age-group specific injury mortality-United States, 1999-2004. MMWR 2007;56:1281-1284

2. CDC. Unintentional poisoning deaths- United States, 1999-2004. MMWR 2007;56:93-96

3. Hu G, Baker SP. Trends in unintentional injury deaths, U.S., 1999-2005: Age, gender, and racial/ethnic differences. Am J Prev Med 2009;37:188-194

4. Hu G, Baker S. Recent increases in fatal and non-fatal injury among people aged 65 years and over in the USA. Inj Prev 2010;16:26-30

5. Jemal A, Ward E, Hao Y, Thun M. Trends in the leading causes of death in the United States, 1970-2002. JAMA 2005;294:1255-1259

6. Paulozzi LJ, Ballesteros MF, Stevens JA. Resent trends in mortality from unintentional injury in the United States. J Safety Res 2006;37:277-283

7. Kannus P, Niemi S, Sievänen H, Parkkari J. Declining incidence in fall-induced deaths of older adults: Finnish statistics during 1971-2015. Aging Clin Exp Res 2018;30:1111-1115

8. Korhonen N, Niemi S, Parkkari J, Palvanen M, Kannus P. Unintentional injury deaths among adult Finns in 1971-2008. Injury 2011;42:885-888

9. Rivara FP, Grossman DC, Cummings P. Injury prevention. First of two parts. N Engl J Med 1997;337:543-548

10. Rivara FP, Grossman DC, Cummings P. Injury prevention. Second of two parts. N Engl J Med 1997;337:613-618 
11. Official Statistics of Finland. Official Cause-of Death Statistics, 1971- 2016. Helsinki: Statistics Finland, 2017

12. Mack K, Clapperton A, Macpherson A et al. Trends in the leading causes of injury mortality, Australia, Canada, and the United States, 2000-2014. Can J Public Health 2017;108:e185-e191

13. Official Statistics of Finland. Structure of Population and Vital Statistics: Whole Country and Provinces, 1971-2016. Helsinki: Statistics Finland, 2017

14. Jylhä M, Vuorisalmi M, Luukkala T et al. Is it possible to improve functional ability in the oldest-old? Study of changes in functional ability of people aged 90 and over in 1996-2007. Finn Med J 2009; 64:2285-2290 (in Finnish)

15. Sulander T, Puska P, Nissinen A et al. Changes in the functional ability of elderly Finns in 1993-2005. Finn Med J 2007; 62:29-33 (in Finnish)

16. Laitalainen E, Helakorpi S, Martelin T, Uutela A. Functional ability among Finnish elderly has improved, though not in all population groups. Finn Med J 2010;65:3295-3301 (in Finnish)

17. Davies JC, Robertson MC, Ashe MC, Liu-Ambrose T, Khan KM, Marra CA. Does a homebased strength and balance programme in people aged $>80$ years provide the best value for money to prevent falls? A systematic review of economic evaluations of falls prevention interventions. Brit J Sports Med 2010;44:80-89

18. Patil R, Kolu P, Raitanen J et al. Cost-effectiveness of vitamin D supplementation and exercise in preventing injurious falls among older home-dwelling women: findings from an RCT. Osteoporos Int 2016;27:193-201

19. Vuori E, Ojanperä I, Nokua J, Ojansivu R-L. Fatal poisoning in Finland during 2005-2007. Finn Med J 2009;64:3187-3195 (in Finnish) 
Fig. 1 Number (A) and incidence rate (per 100,000 individuals) (B) of the most frequent unintentional injury deaths in Finland among women 15 years of age or older in 1971-2016. 
(A) Number

800

700

600

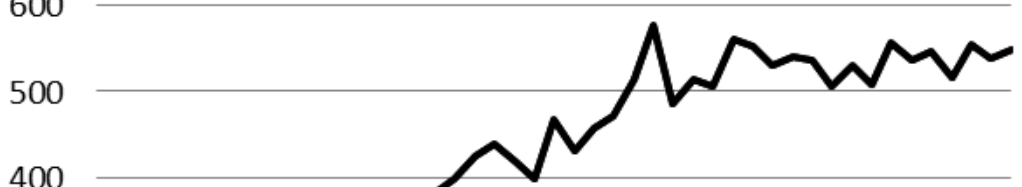

400

300

200

100

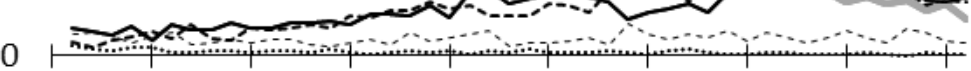

1970197519801985199019952000200520102015

Year

- Falls

---. Alcohol poisonings

Road traffic crashes

- Other poisonings

-...-. Drownings

(B) Incidence

Water traffic crashes

50

40

30

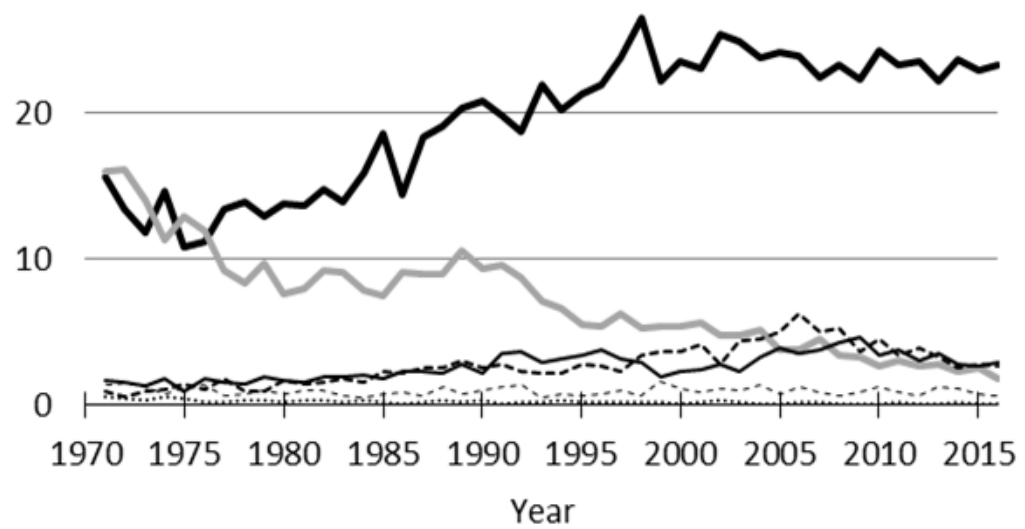

Fig. 2 Number (A) and incidence rate (per 100,000 individuals) (B) of the most frequent unintentional injury deaths in Finland among men 15 years of age or older in 1971-2016. 
(A) Number

MEN

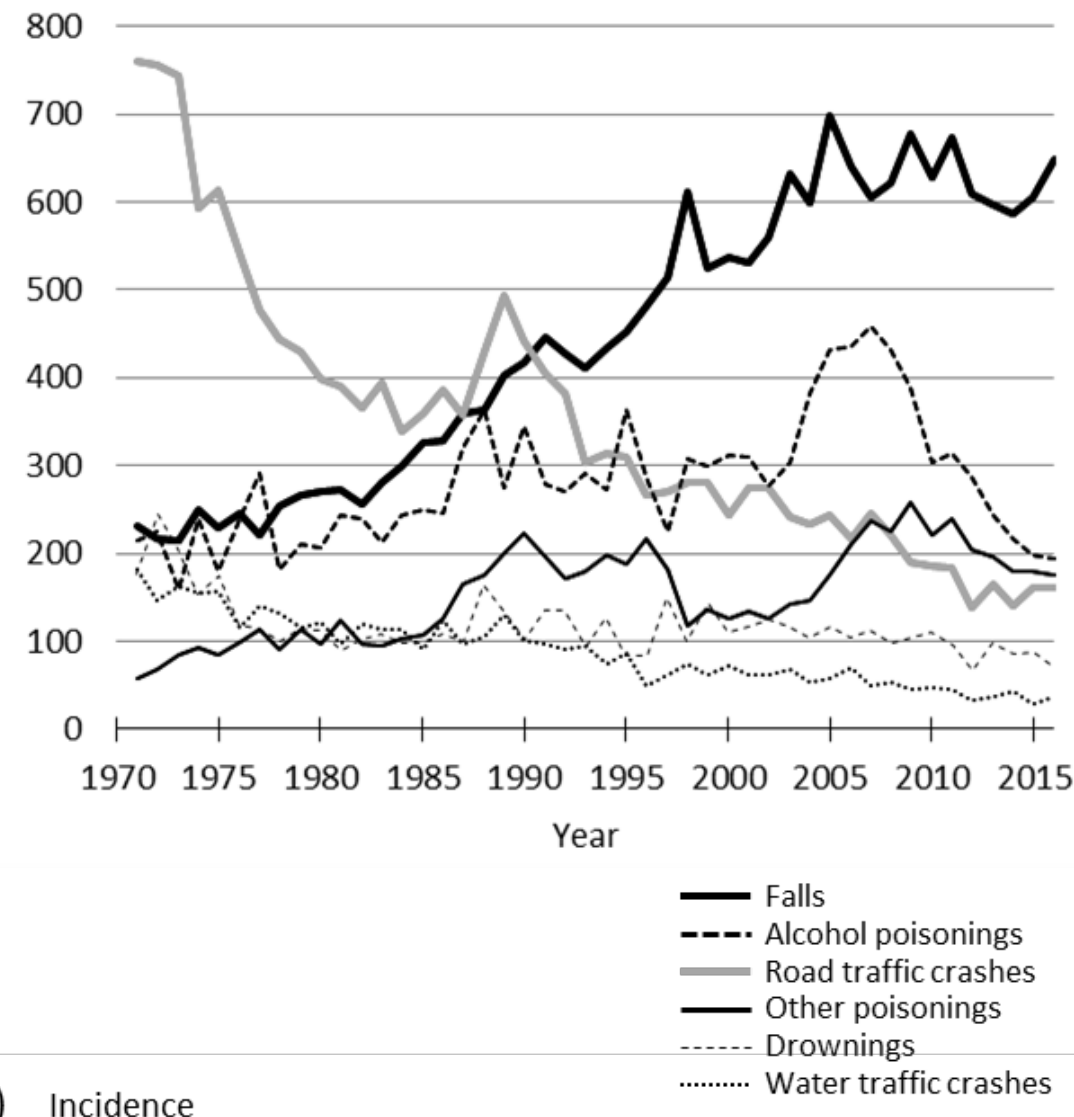

(B) Incidence

Water traffic crashes

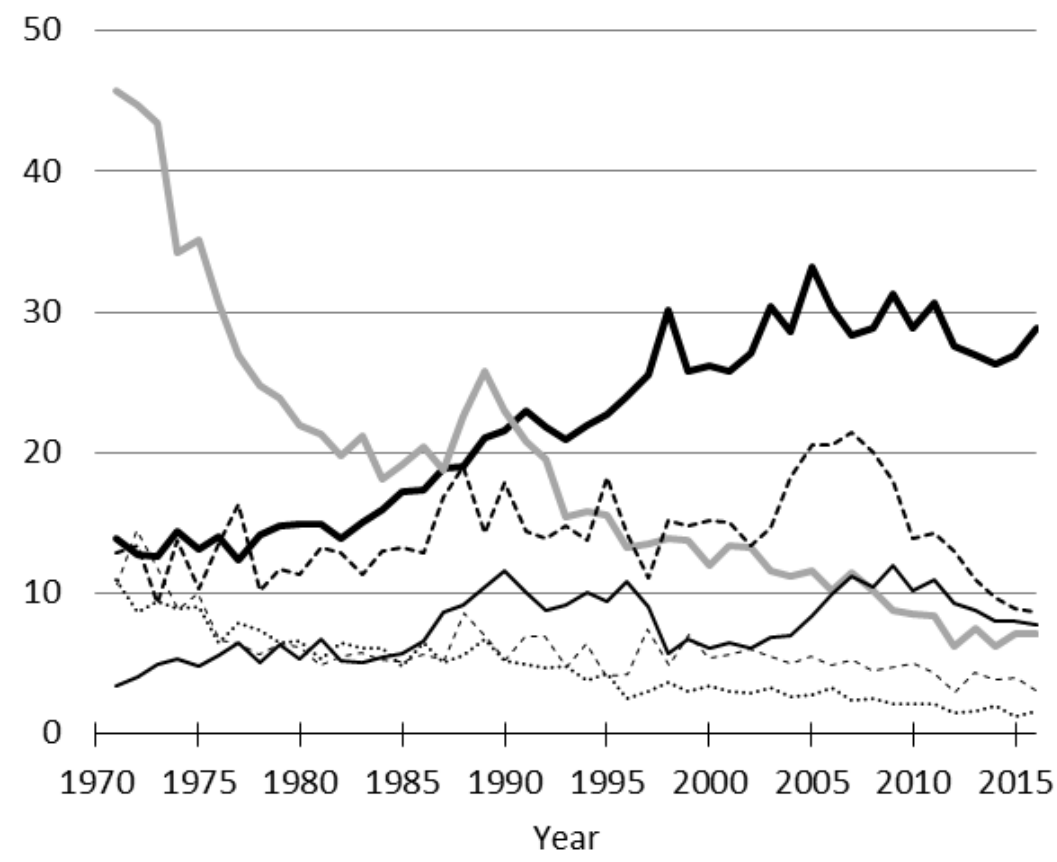

